\title{
ESTUDO DE ADEQUAÇÃO DO MANUAL DE ACESSIBILIDADE ESCOLAR - NBR9050:2015
}

\author{
PEREIRA, Jennifer Kaoana (1); \\ PFUTZENREUTER, Andréa Holz (2)
}

(1) Universidade Federal de Santa Catarina, Graduanda em Engenharia de Infraestrutura

e-mail:jenniferkpereira@hotmail.com

(2) Universidade Federal de Santa Catarina, Doutora em Arquitetura e Urbanismo

e-mail:andrea.hp@ufsc.br

\begin{abstract}
RESUMO
O Programa Acessibilidade nas Escolas implementado em 2011 está direcionado a promoção dos direitos ao acesso espacial e as demais formas de inclusão social nos estabelecimentos educacionais de Santa Catarina. Por meio de Manual apresenta um checklist à análise e avaliação de escola acessível. Este artigo compara a atualização do checklist de acordo com a ABNT NBR 9050 publicada em 2015 e a sua remodelação com a finalidade de facilitar sua utilização. A aplicabilidade do novo checklist foi testada na Escola de Educação Básica Professora Antonia Gasino de Freitas, Lajeado Grande (SC), a qual promoveu adaptações e resultados de interferências.
\end{abstract}

Palavras chave: Acessibilidade. Escolas. NBR 9050. Inclusão Social.

\begin{abstract}
The Accessibility in Schools Program created in 2011 is directed to the promotion of the rights to the spatial accessibility and other forms of social inclusion in the educational establishments in Santa Catarina. The manual provides a checklist which purposal is to analyze and evaluation of a acessible school. This article aims to update the accessibility manual according to ABNT NBR 9050 published in 2015 and remodelling in order to make its use easier. The usability was analised by the applience at Escola de Educação Básica Professora Antônia Gasino de Freitas, Lajeado Grande (SC). It promoted adaptations and interference results.
\end{abstract}

Keywords: Accessibility. Schools. NBR 9050. Social Inclusion.

\section{INTRODUÇÃO}

A presença de alunos com deficiência nas escolas comuns tem se tornado comum, enfatizando a importância da inclusão social e da acessibilidade em todos os sentidos. Relembrando o artigo 205 da Constituição Federal Brasileira, garantir a educação para todos é um dever do Estado para o "(...) pleno desenvolvimento da pessoa, ser preparo para o exercício da cidadania e sua qualificação para o trabalho" (BRASIL, 1988)

De maneira geral, as mudanças que ocorrem ao longo da vida podem estar vinculadas à redução da mobilidade do individuo. Todas as pessoas, independente de idade, sexo, credo, cor, condição social ou deficiência, tem direito à igualdade assegurado pela Constituição 


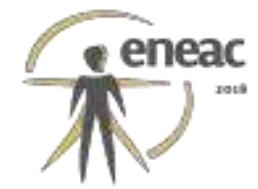

Brasileira de 1988. Para possibilitar essa inclusão e oferecer a todos o direito de ir e vir de modo autônomo, seguro e sem esforços desnecessários, as mudanças precisam abranger além das questões culturais (CAMBIAGHI, 2007; DISCHINGER; ELY; PIARDI, 2012; PRADO; LOPES; ORNSTEIN, 2010).

William Loughborough (2000), assegura que a acessibilidade é um direito, não um privilégio.

A necessidade de inclusão social fez com que em meados da década de 1980, o debate sobre o tema se popularizasse. Em 1985 foi publicada pela Associação Brasileira de Normas Técnicas (ABNT) a NBR 9050 - Adequação das edificações, equipamentos e mobiliário urbano à pessoa portadora de deficiência; em razão da institucionalização pela Organização das Nações Unidas do Ano Internacional das Pessoas Deficientes em 1981; e pela criação do Programa de Ação Mundial (PAM) para as pessoas com deficiência.

A primeira revisão da Norma Brasileira (NBR) 9050:1985 começou em 1991 e foi concluída em 1994. Neste mesmo período, outras normas relacionadas à acessibilidade estavam em elaboração e, devido ao interesse no assunto, em 2000 foi criado o Comitê Brasileiro de Acessibilidade.

De acordo com Cambiaghi (2007) após a segunda revisão em 2004, a norma ficou mais completa e próxima ao aplicado em outros países. Contudo, sabe-se que para atender o ideal de cidade adequada para todos, vários aspectos precisam ser considerados, como vontade politica e legislação adequada.

Segundo Prado, Lopes e Ornstein (2010), a versão da norma publicada em 2004 tem seu titulo modificado para Acessibilidade a edificação, mobiliário, espaços e equipamentos urbanos, onde além de incorporar novas tecnologias e produtos, reforça o conceito de acessibilidade para todos e não apenas portadores de deficiências.

A normatização ganhou caráter de lei com a publicação do decreto 5296 de 2005, que regulamentou os critérios básicos para acessibilidade. Assim, todas as construções aprovadas a partir de 2004 precisam atender a Norma Técnica 9050, que rege os critérios básicos para acessibilidade.

Santos Filho (2010) afirma que apesar de ser inegável o processo que a acessibilidade teve Brasil, ainda são poucos os espaços significantemente acessíveis.

A dinâmica das construções e o surgimento de novas leis implicam em uma desatualização da norma de acordo com as condições atuais. Depois de onze anos a NBR 9050 teve sua terceira revisão publicada em 2015.

Nos anexos da nova norma brasileira de acessibilidade (revisão de 2015), está o conceito de desenho universal e seus princípios, e a consideração de fatores relevantes de projeto. $O$ novo texto evoluiu no sentido de ser mais explicativo e de detalhar a informação, abandonando uma abordagem cartesiana de enfatizar a acessibilidade arquitetônica e urbanística (COHEN, 2015).

A nova norma ressalta critérios de sinalização em espaços públicos, parâmetros de ergonomia para mobiliário e equipamentos urbanos, intervenções em bens tombados pelo patrimônio histórico. Além de considerar as pessoas com deficiência, a abordagem foi ampliada para aqueles que têm dificuldades para se locomover - como idosos, obesos, gestantes (ARQBACANA, 2015).

Figueiredo (2015) analisou as mudanças entre a segunda e a terceira revisão da norma. $E$ declarou que de maneira geral a norma melhorou por sua completude e detalhamento

A inclusão é um movimento mundial que condena toda forma de segregação e exclusão. A constituição brasileira assegura, desde 1988, o direto à educação para todos, sem nenhum tipo de descriminação. 


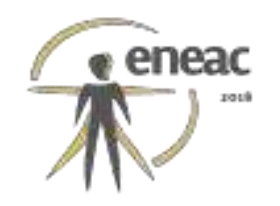

Em 2011, o governo do Estado de Santa Catarina criou o programa de acessibilidade nas escolas, que conta com um Manual de acessibilidade escolar, que tem como objetivo mostrar a importância da inclusão social e da educação inclusiva, além de analisar à escola quanto à acessibilidade.

Nesta perspectiva, o objetivo deste artigo é, apresentar as alterações necessárias para atualizar o checklist proposto pelo manual com as atualização da NBR9050 em 2015, aplicando-o na Escola de Educação Básica Professora Antônia Gasino de Freitas para verificar sua aplicabilidade.

\section{MANUAL DE ACESSIBILIDADE NAS ESCOLAS}

No ano de 2011, o Ministério Público de Santa Catarina (MPSC), criou o programa "Acessibilidade das escolas de Santa Catarina", programa que visa promover os direitos ao acesso espacial e às demais formas de inclusão social nos estabelecimentos educacionais públicos e privados do estado, criando o Manual de Acessibilidade nas Escolas.

O Manual de Acessibilidade nas Escolas surgiu em parceria da Presidência da Republica, Ministério da Educação, Secretaria Executiva, Secretaria da Educação Especial e a Universidade Federal de Santa Catarina. O mesmo foi escrito no ano de 2009 por Marta Dischinger, Vera Helena Moro Bins Ely e Monna Michelle Faleiros da Cunha Borges.

O principal objetivo deste manual foi fornecer conhecimentos básicos que permitam a identificação das dificuldades encontradas por alunos com necessidades especiais na utilização de espaços e equipamentos, auxiliando na identificação do problema, e tornando mais simples encontrar uma solução para o mesmo, sendo este o primeiro passo para desenvolver soluções para minimizar ou eliminar as barreiras físicas.

Este manual está estruturado em cinco partes. Na primeira parte são apresentados os principais conceitos de acessibilidade e inclusão social, para permitir a compreensão do problema. $\mathrm{Na}$ segunda parte são ilustrados os principais problemas e as respectivas soluções para cada um dos casos. Na terceira parte estão inclusas orientações gerais para complementar informações específicas. Na quarta parte são apresentadas planilhas de avaliação que visam apoiar a verificação dos problemas na escola a partir das leis e normas existentes quanto à acessibilidade dividindo-as em 17 ambientes, de forma a serem analisados separadamente.

Com o propósito de atualizar o checklist fornecido pelo manual de acessibilidade escolar de acordo com a norma vigente no ano de 2017 a NBR 9050/2015. Nota-se que alguns itens que antes faziam apenas parte do Decreto 5.296/04, foram inclusos na NBR 9050 e houveram mudanças em dimensões de referência, tais como desníveis máximos e faixa de altura de maçaneta.

Como o checklist proposto pelo manual escolar foi produzido de forma a não inserir os dados da norma no próprio checklist, as mudanças não são facilmente vistas nesta atualização, o que pode parecer erroneamente que as alterações foram pequenas. Isso acontece em virtude do modelo do formulário. A maior parte alterações foram em seções onde se encontram as informações, como exemplificado na figura 1. 


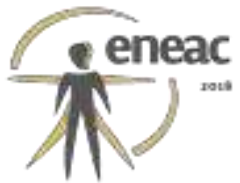

Figura 1 - Trecho da atualização do checklist existente

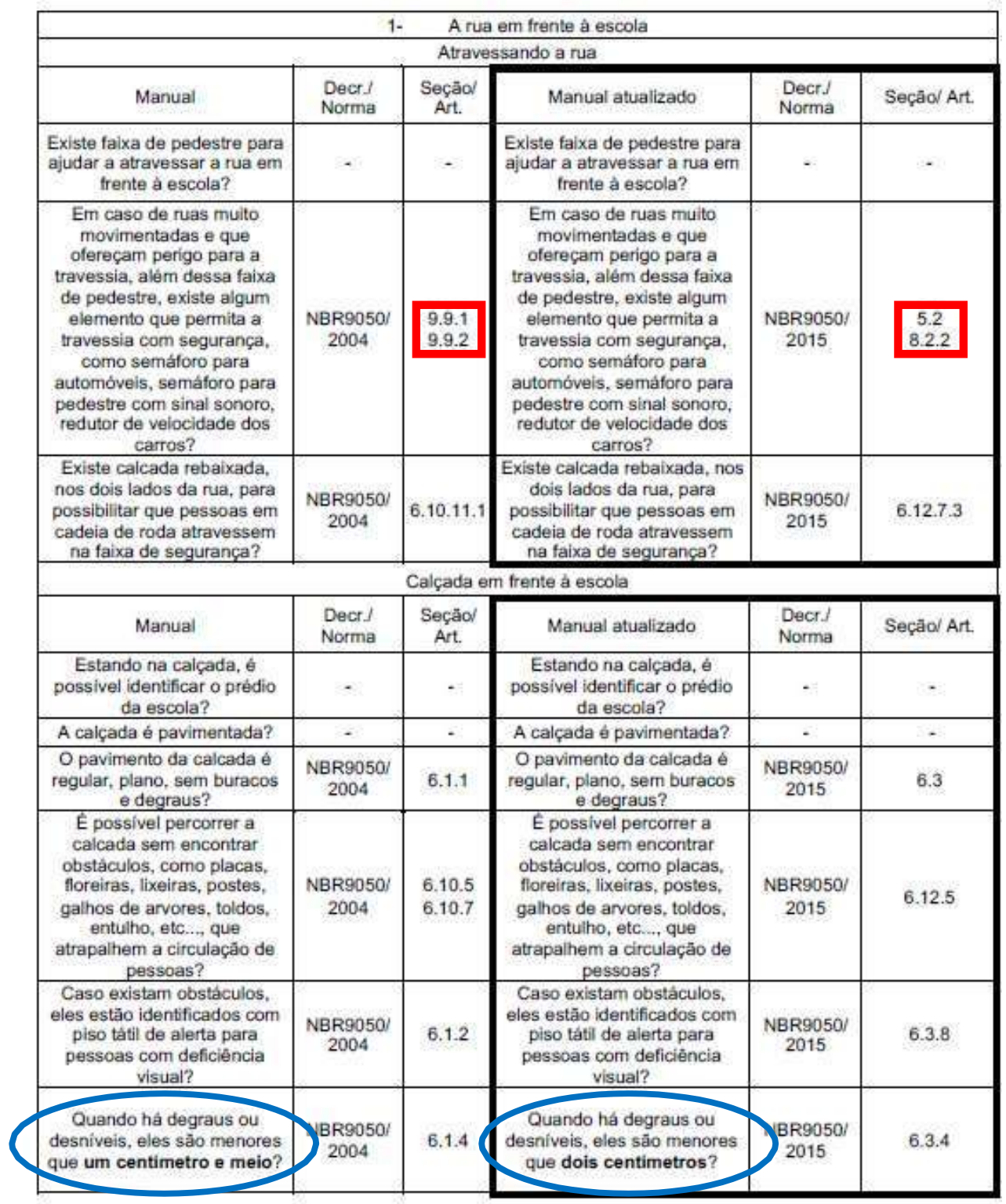

Fonte: DISCHINGER, ELY e BORGES (2009) adaptado pela autora (2017)

A figura acima apresenta um quadro comparativo que tem a importância de apresentar algumas das mudanças que ocorreram no checklist com a revisão da norma NBR9050, e guiar o usuário para que ele encontre as informações necessárias na norma atual de maneira mais eficiente. A atualização completa encontra-se em material publicado pela autora em seu trabalho de conclusão de curso.

Embora o checklist proposto no Manual realize sua função, ainda é amplo e poderia melhorar na clareza de alguns itens. Desta forma, surge a oportunidade de analisar o check list existente e propor uma nova ferramenta em que evite a necessidade de ter a norma em mãos e recorrer as suas informações. Para evitar esse esforço e tornar mais prática a sua utilização, as principais informações foram inseridas no próprio sistema de checagem.

A proposta é baseada em, preencher a informação de acordo com o caso em que está sendo aplicado e conferir com as medidas sugeridas pela NBR 9050/2015, e posteriormente 


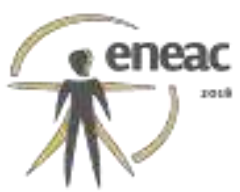

verificar se o caso está ou não em conformidade, minimizando a necessidade de buscar estas informações na norma.

\section{VALIDAÇÃO DO MÉTODO}

O checklist proposto foi aplicado na Escola de Educação Básica Professora Antônia Gasino de Freitas. A escola possui 1.118,15 $\mathrm{m}^{2}$ de área construída. Para o reconhecimento do espaço e uma breve análise das condições físicas da mesma, foi aplicada a técnica de Walkthrough, com auxílio de registros fotográficos, inspeção in-loco e entrevistas com o dirigente do local.

As condições atuais foram avaliadas por conforme ou não conforme com o que é requerido pela NBR 9050/2015 e pelo Decreto 5.296/2004, como pode ser visualizado na figura 2 . Os resultados podem ser apresentados de uma maneira mais visual, utilizando gráficos e cores, sendo possível compreender a situação do objeto de estudo.

Figura 2 - Trecho do Checklist proposto

\begin{tabular}{|c|c|c|c|}
\hline & & Elementos e parâmetros & \\
\hline & Item & NBR 9050/2015 & Situação \\
\hline & Sinalização visual & Por meio de textos e símbolos & Conforme ( ) Não Conforme ( ) \\
\hline & Sinalização tátil & Informações em relevo & Conforme ( ) Não Conforme ( ) \\
\hline & Largura da porta: $\quad$ (cm) & mínimo $80 \mathrm{~cm}$ & Conforme ( ) Não Conforme ( ) \\
\hline & $\begin{array}{l}\text { Desnível entre corredor e sala de } \\
\text { aula: } \quad(\mathrm{cm})\end{array}$ & máximo $0,5 \mathrm{~cm}$ & Conforme ( ) Não Conforme ( ) \\
\hline$\frac{\pi}{\pi}$ & Mobiliário & & \\
\hline$\underset{0}{0}$ & Altura da lousa: $\quad$ (cm) & altura inferior máxima de $90 \mathrm{~cm}$ & Conforme ( ) Não Conforme ( ) \\
\hline$\frac{\pi}{\pi}$ & $\begin{array}{l}\text { Espaço livre em frente a lousa: } \\
(\mathrm{cm})\end{array}$ & diâmetro de $150 \mathrm{~cm}$ & Conforme ( ) Não Conforme ( ) \\
\hline & Altura das estantes: $\quad$ (cm) & máximo $135 \mathrm{~cm}$ & Conforme ( ) Não Conforme ( ) \\
\hline & Altura da carteira: $\quad(\mathrm{cm})$ & mínimo 73 cm & Conforme ( ) Não Conforme ( ) \\
\hline & Largura da carteira: $\quad(\mathrm{cm})$ & mínimo $80 \mathrm{~cm}$ & Conforme ( ) Não Conforme ( ) \\
\hline & $\begin{array}{l}\text { Profundidade da carteira: } \\
(\mathrm{cm})\end{array}$ & $\begin{array}{l}\text { mínimo } 50 \mathrm{~cm} \text {, recomendável } 60 \\
\mathrm{~cm}\end{array}$ & Conforme ( ) Não Conforme ( ) \\
\hline & $\begin{array}{l}\text { Espaço entre carteiras: } \\
\text { (cm) }\end{array}$ & mínimo $90 \mathrm{~cm}$ & Conforme ( ) Não Conforme ( ) \\
\hline & $\begin{array}{l}\text { Carteira adaptável quanto ao } \\
\text { tamanho dos alunos: }\end{array}$ & Mínimo uma & Conforme ( ) Não Conforme ( ) \\
\hline
\end{tabular}

Fonte: A autora (2017)

O checklist proposto apresenta as informações da NBR9050 de 2015 com as medidas mínimas exigidas, bem como no Campo de identificação do Item avaliado um espaço para anotar a medição realizada. Isto para agilizar as sugestões de alterações, adaptações ou reformas necessárias à adequação a norma.

O mesmo pode também justificar a conformidade do local no momento de sua medição, caso alguma alteração tenha sido realizada após o levantamento em campo, o relatório final justifica a análise das conformidades. 
Para melhor visualização das informações de análise e verificação foram definidos três tipos de identificação: a) conforme (cor verde) e b) não conforme (cor vermelha), como apresentado na figura 3.

Figura 3 - Visualização da Análise da sala de Aula

\begin{tabular}{|c|c|c|}
\hline \multirow{12}{*}{$\begin{array}{l}\frac{\pi}{J} \\
\text { ॠ } \\
\frac{0}{0} \\
\frac{\pi}{\pi} \\
\omega\end{array}$} & \multicolumn{2}{|l|}{ Elementos e parâmetros } \\
\hline & & Situação \\
\hline & Sinalização visual & \\
\hline & Sinalização tátil & \\
\hline & Largura da porta: $80(\mathrm{~cm})$ & \\
\hline & Desnivel entre corredor e sala de aula: $5(\mathrm{~cm})$ & \\
\hline & 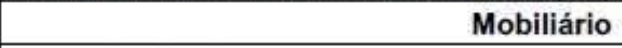 & \\
\hline & Altura da lousa: $88(\mathrm{~cm})$ & \\
\hline & Espaço livre em frente a lousa: $150(\mathrm{~cm})$ & \\
\hline & Altura das estantes: $185(\mathrm{~cm})$ & \\
\hline & Altura da carteira: $76(\mathrm{~cm})$ & \\
\hline & Largura da carteira: $60(\mathrm{~cm})$ & \\
\hline
\end{tabular}

Fonte: A autora (2017)

De acordo com a analise realizada de 160 itens, apenas 52 estavam de acordo com o proposto na NBR 9050/2015, o que significa que quase $67,5 \%$ dos itens precisam ser adaptados para estarem em conformidade com a norma, e também com a lei.

O entorno, apesar de não fazer parte da escola, foi o primeiro a ser analisado, pois não é possível chegar na escola sem que este esteja acessível. A situação apresentada evidencia os problemas que impedem a mobilidade urbana e o acesso escolar.

A entrada principal dos alunos na escola está inutilizada, por se tratar de uma escada irregular, tanto na altura dos espelhos dos degraus e quanto de dimensionamento do piso. Além de não apresentarem corrimão de segurança e piso tátil. Os alunos acessam pelo estacionamento da escola compartilhando o espaço com os veículos.

A recepção e as salas de atendimentos são ambientes importantes, pois realizam o atendimento público em geral, portanto, é essencial que as mesmas estejam adequadas para recepcionar a todos, sem restrições.

O corredor é o espaço de conexão e onde todos os usuários da escola devem ter a capacidade de andar livremente sem a existência de obstáculos. Durante a verificação, constatou-se que o corredor não existe guarda-corpo ou corrimão nem sinalização.

Nos sanitários as inconformidades estão em maior parte na sinalização e na adequação do mobiliário, na instalação das barras de apoio e na área livre do mictório masculino.

As salas de aula estão quase totalmente não conforme. Sendo as inconformidades relacionadas à sinalização, desnível entre sala e corredor, e as dimensões do mobiliário. Os laboratórios apresentam situação semelhante às salas de aula, incluindo a questão de dimensionamento do mobiliário.

A biblioteca e a sala de recursos tem suas inconformidades na falta de sinalização, irregularidades no mobiliário e a ausência de tecnologia assistiva. 


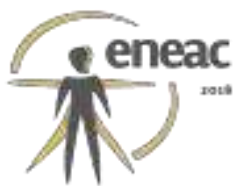

O refeitório possui suas não conformidades na parte da sinalização e irregularidade do mobiliário. As mesas têm bancos fixos e não permitem a aproximação de cadeira de rodas.

A rampa que está anexa ao acesso secundário à escola, apresenta irregularidade em sua largura, na ausência de corrimão e no piso tátil.

O pátio apresenta ausência de sinalização, das placas indicativas e do piso tátil. Além da falta das grades de proteção. O material do piso do pátio aberto é brita média, o dificulta o uso independente de uma cadeira de rodas ou para quem tem alguma mobilidade reduzida.

\section{ANÁLISE E CONSIDERAÇÕES}

A atualização do manual foi realizada de maneira simples e prática, verificando todos os elementos na norma vigente e comparando com a anterior. A diferença não foi muito visível devido ao modelo do checklist que não possuía muitas informações inseridas no mesmo. Entretanto, por ser uma referência para ambientes escolares, sua atualização é necessária para que seja continuamente aplicada pelas Secretarias de Educação, Órgãos fiscalizadores como vigilância sanitária; Departamentos de Projetos das Prefeituras e Instituições estaduais e federais.

O checklist proposto exibe as recomendações da norma de maneira sucinta e dinâmica à adaptação dos espaços para que possam ser utilizados por todas as pessoas sem que haja diferenciação. Ao analisar um local com o auxílio do checklist consegue-se avaliar o atendimento as normativas e identificar os pontos críticos, sem que seja necessária a utilização constante do manual, como apresentado na figura 4 e 5.

Figura 4 - Trecho do Checklist Existente e sua atualização referente a Biblioteca

\begin{tabular}{|c|c|c|c|c|c|}
\hline \multicolumn{6}{|c|}{ 10- Biblioteca } \\
\hline Manual & $\begin{array}{l}\text { Decr] I } \\
\text { Norma }\end{array}$ & $\begin{array}{c}\text { Seçäo/ } \\
\text { Art. }\end{array}$ & Manual atualizado & $\begin{array}{l}\text { Decrf } \\
\text { Norma }\end{array}$ & Seçâol Art. \\
\hline $\begin{array}{c}\text { No ambiente da biblioteca, } \\
\text { há contraste de cor entre } \\
\text { piso, parede e moveis, para } \\
\text { facilitar a orientaçäo de } \\
\text { pessoas com baixa visāo? }\end{array}$ & $x$ & $x$ & $\begin{array}{c}\text { No ambiente da biblioteca, } \\
\text { há contraste de cor entre } \\
\text { piso, parede e moveis, para } \\
\text { facilitar a orientação de } \\
\text { pessoas com baixa visão? }\end{array}$ & $x$ & $x$ \\
\hline $\begin{array}{c}\text { E possivel a pessoa, em } \\
\text { cadeira de rodas, circular e } \\
\text { manobrar pela sala ate os } \\
\text { diferentes locais de } \\
\text { atividades, como mesas de } \\
\text { trabalho e de computador, } \\
\text { estantes, balcầo de } \\
\text { empréstimo? }\end{array}$ & $\begin{array}{c}\text { NBR } \\
9050 / 2004\end{array}$ & 4.3 .1 & $\begin{array}{l}\text { E possivel a pessoa, em } \\
\text { cadeira de rodas, circular e } \\
\text { manobrar pela sala ate os } \\
\text { diferentes locais de } \\
\text { atividades, como mesas de } \\
\text { trabalho e de computador, } \\
\text { estantes, balcäo de } \\
\text { empréstimo? }\end{array}$ & $\begin{array}{c}\text { NBR } \\
9050 / 2015\end{array}$ & 4.3 .1 \\
\hline $\begin{array}{c}\text { As mesas de estudo ou de } \\
\text { computador estäo livres de } \\
\text { qualquer obstáculo, como } \\
\text { pés e gaveteiros que } \\
\text { impeçam a aptoximação de } \\
\text { pessoas em cadeira de } \\
\text { rodas? }\end{array}$ & $\begin{array}{c}\text { NBR } \\
9050 / 2004\end{array}$ & 8.7 .2 & $\begin{array}{c}\text { As mesas de estudo ou de } \\
\text { computador estäo livres de } \\
\text { qualquer obstáculo, como } \\
\text { pés e gaveteiros que } \\
\text { impeçam a aproximaçāo de } \\
\text { pessoas em cadeira de } \\
\text { rodas? }\end{array}$ & $\begin{array}{c}\text { NBR } \\
9050 / 2015\end{array}$ & 10.16 .3 \\
\hline $\begin{array}{c}\text { Existem mesas com altura } \\
\text { adequada ao uso de pessoas } \\
\text { ern cadeira de rodas ou baixa } \\
\text { estatura? }\end{array}$ & $x$ & $x$ & $\begin{array}{c}\text { Existem mesas com altura } \\
\text { adequada ao uso de pessoas } \\
\text { em cadeira de rodas ou baixa } \\
\text { estatura? }\end{array}$ & $\begin{array}{c}\text { NBR } \\
9050 / 2015\end{array}$ & 10.16 .6 \\
\hline
\end{tabular}

Fonte: DISCHINGER, ELY e BORGES (2009) adaptado pela autora (2017) 


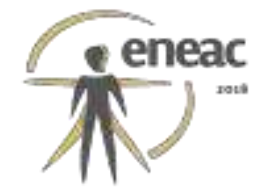

Figura 5 - Trecho do Checklist Proposto referente à Biblioteca

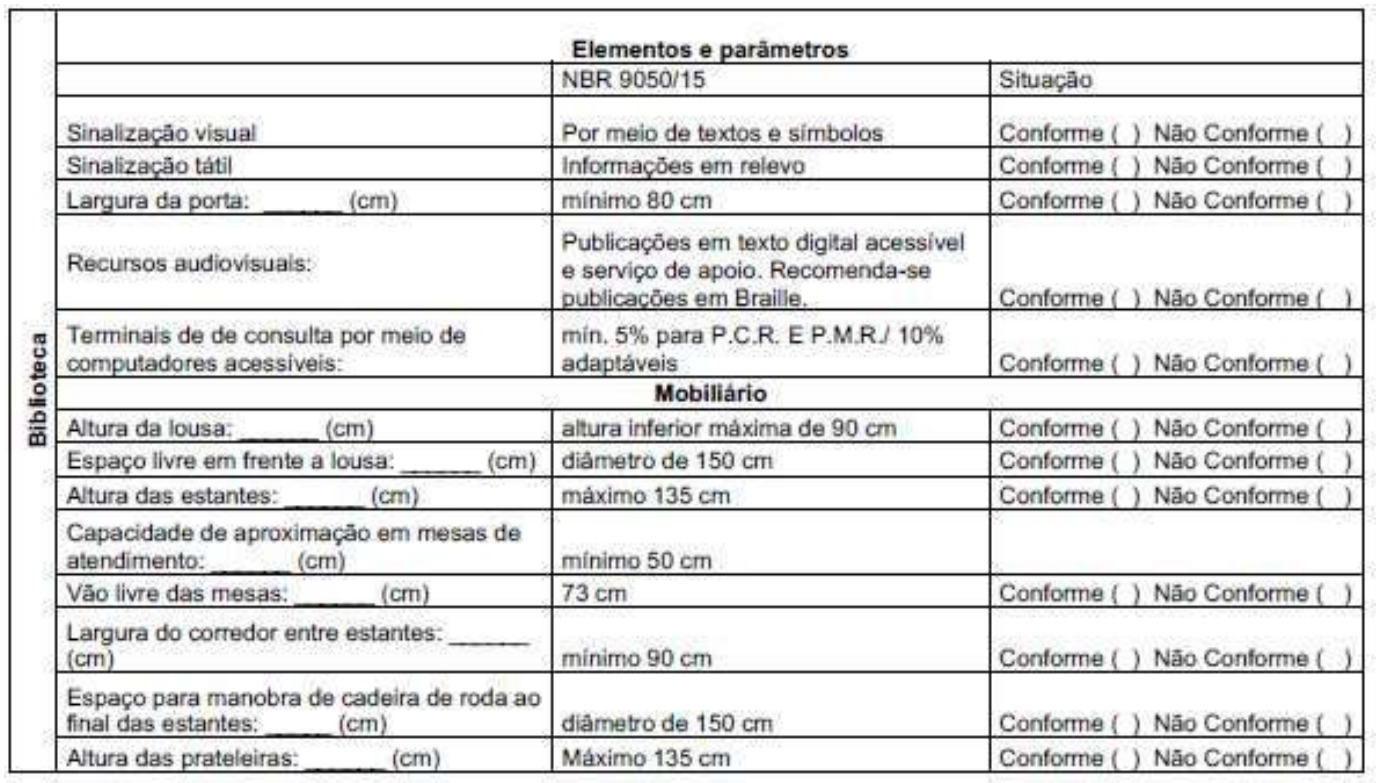

Fonte: A autora (2017)

O intuito a que se propôs o trabalho foi atingido apresentando a viabilidade de atualização do Manual de Acessibilidade Escolar, mas principalmente percebendo que a alteração do checklist pode aprimorar a aplicabilidade das normativas. A utilização de planilhas dinâmicas ou aplicativos tornam o método ainda mais eficaz.

A acessibilidade é um importante fator que influencia na inclusão social. O atendimento às normas estabelecidas garante as condições mínimas para que todos possam exercer as atividades básicas dentro da escola.

Embora saibam das mudanças necessárias, é natural que não ocorram de forma instantânea. De acordo com Carstens (2017), o processo faz parte de uma mudança cultural, e aos poucos os profissionais passam a integrar nos projetos de infraestrutura os itens necessários para obedecer a legislação.

Uma vez que as alterações necessárias foram apresentadas, o impasse encontrado pelas instituições é financeiro e como realizá-las de maneira que não prejudique a realização das aulas, ou seja, fazendo isso da maneira mais rápida possível. Lembrando que a maioria das edificações públicas de ensino estão ambientadas em prédios antigos, os quais não foram projetados à acessibilidade e suas estruturas não facilitam a adequação.

\section{REFERÊNCIAS BIBLIOGRÁFICAS}

ARAUJO, Eliece Helena Santos. Acessibilidade e inclusão de pessoas com deficiência na faculdade de direito da UFBA. 2015. 86 f. Dissertação (Mestrado) -Programa de Pós-Graduação em Estudos Interdisciplinares sobre a Universidade,Curso de Direito, Universidade Federal da Bahia, Salvador, 2015.

BRASIL. Constituição (1988). Constituição da República Federativa do Brasil. Brasília, DF: Senado Federal: Centro Gráfico, 1988. 292 p.

BRASIL. Ministério da Educação. Secretaria de Educação Especial. A pessoa com necessidades educacionais especiais: Deficiência Física. Brasília - DF: 2006. Disponível em: <http://portal.mec.gov.br/seesp/arquivos/pdf/deffisica.pdf>. Acesso em: 02 jun. 2017. 


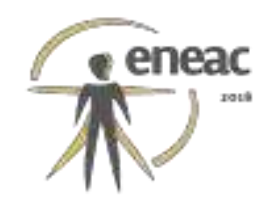

BRASIL. Ministério da Educação. Secretaria de Educação Especial. Formação. Brasília, DF: . Disponívelem:<http://portal.mec.gov.br/seesp/arquivos/pdf/aee_df.pdf>. Acesso em:02jun. 2017.

CAMBIAGHI, Silvana. Desenho Universal: Métodos e técnicas para arquitetos e urbanistas. São Paulo: Editora Senac, 2007. 269 p.

CASTRO, Jary de Carvalho e. IR E VIR: Acessibilidade, compromisso de cada um.Campo Grande: Gibim Gráfica e Editora Ltda., 2013. 128 p.

COHEN, Regina. O que mudou com a nova norma de acessibilidade? 2015. Disponível em: <http://www.inclusive.org.br/arquivos/28484>. Acesso em: 02 jun. 2017.

DISCHINGER, Marta; ELY, Vera Helena Moro Bins; BORGES, Monna Michelle Faleiros da Cunha. Manual de acessibilidade espacial para escolas: $O$ direito à escola acessível! Brasília: Ministério da Educação, Secretaria de Educação Especial, 2009. 115 p.

DISCHINGER, Marta; ELY, Vera Helena Moro Bins; PIARDI, Sonia Maria Demeda Groisman. Promovendo acessibilidade espacial nos edifícios públicos: Programa de Acessibilidade às pessoas com deficiência ou mobilidade reduzida nas edificações de uso público. Florianópolis: MPSC, 2012. $161 \mathrm{p}$.

FURRER, Maria Alice. Atualização da norma técnica de acessibilidade. 2015. Disponível em: $<$ http://www.acessibilidadenapratica.com.br/textos/atualizacao-da-norma-tecnica-de-acessibilidade/>. Acesso em: 05 jun. 2017.

MAZZONI, Alberto Angel et al. Aspectos que interferem na construção da acessibilidade em bibliotecas universit rias. Ci. Inf., Bras lia, v. , n. , p. 9- , maio ago. 1. Dispon vel em: <http://www.scielo.br/pdf/ci/v30n2/6209.pdf>. Acesso em: 31 maio 2017.

PRADO, Adriana R. de Almeida; LOPES, Maria Elisabete; ORNSTEIN, Sheila Walbe. Desenho universal: caminhos da acessibilidade no Brasil. Butantã: Annablume, 2010.

SASSAKI, Romeu Kazumi. Inclusão no lazer e turismo: em busca da qualidade de vida. São Paulo: Áurea, 2003. $\overline{\text { set. } 2004 .}$

Pessoas com deficiência e os desafios da inclusão. Revista Nacional de Reabilitação, 30 